\title{
Features of Educational Attainment and Job Promotion Prospects ${ }^{1}$
}

\author{
Seymour Spilerman \\ Columbia University \\ Tormod Lunde \\ University of Oslo
}

\begin{abstract}
In much sociological research on occupational achievement it is presumed that the full effect of education can be understood from an examination of years of schooling. It is also commonly assumed that the impact of education on career development can be investigated without reference to an individual's current organizational rank. This article shows that, with reference to promotion, several features from an employee's educational biography will influence his or her rate of advancement. It is also shown that the returns to years of schooling - and to other educational measures - vary with organizational rank; indeed, employers do not reward educational attainment indiscriminately, but only when it is likely to contribute to productivity. In conclusion, it is noted that whereas the "jobmatching" literature argues that the rate of mobility is greatest when the fit between an individual's resources and a job's requirements is poor, the results with regard to promotion suggest that the converse is true.
\end{abstract}

\section{INTRODUCTION}

While there is a considerable literature that documents the impact of education on earnings, occupational status, and the likelihood of promotion (e.g., Mincer 1974; Blau and Duncan 1967; Jencks et al. 1972; Rosenbaum 1979; Wise 1975b), the assessments differ concerning which facets of educational achievement are, in fact, rewarded in the marketplace. In the status-attainment literature it is commonly assumed that a single

\footnotetext{
${ }^{1}$ This research was supported by National Institute on Aging grant AG04367 and by National Science Foundation grant SES-82-18534. We wish to thank Jaesoon Rhee, Yuki Yasuda, Shinkap Han, and Patrick Ball for thoughtful and careful assistance with the computations. We also acknowledge the advice of Trond Petersen, Mark Killingsworth, and Nachum Sicherman. The conclusions are the sole responsibility of the authors.
}

(C) 1991 by The University of Chicago. All rights reserved.

0002-9602/92/9703-0004\$01.50

AJS Volume 97 Number 3 (November 1991): 689-720 
summary measure - years of schooling - captures the full effect of education (Faia 1981). Economists are more sensitive to the different dimensions of education and distinguish between general and firm-specific training, while also noting that labor force experience frequently can be substituted for schooling (Blaug 1976; Sicherman 1991).

Both economists and sociologists have examined the effects of educational credentials, viewed separately from years of schooling. It has been argued that certification (whether high school completion or a college degree) conveys information to the effect that the minimum standard of performance for the credential has been met (Layard and Psacharopoulos 1974; Faia 1981; Collins 1979). Spence (1973) and Arrow (1973), among others, view credentials as a "signal" to a prospective employer about the competence of a job applicant, important to the extent that more reliable indicators are lacking. Presumably, after employment, with the passage of time, the significance of a credential would be superceded by direct measures of performance. Nonetheless, there is evidence that some firms continue to reward credentials, as a matter of policy, over the full course of a worker's career (Spilerman 1986).

The issue of educational quality has also been a focus of research. This theme has been articulated in two ways. It has arisen in explanations of the generally smaller income returns to education among certain ethnic minorities; the thesis offered is that, because of residential segregation, blacks and Hispanics, especially, have limited access to good schools and hence receive inferior training (Reynolds 1978, pp. 266-67; Welch 1973, pp. 893-907). The issue of quality has also been invoked in explanations of the differential returns to education by labor-market sector (Wachter 1974, pp. 651-58), a topic to which we turn momentarily. A related question concerns the impact of prestige of the undergraduate school, an indicator of status affiliations, as well as, presumably, of institutional quality (Kanter 1977; Collins 1979, pp. 35-43).

Less attention has been given to investigating the returns to education in different work settings. There are hypotheses regarding possible variations in the effect of schooling among work positions, such as the formulations of dual labor market theorists (Osterman 1975; Tolbert, Horan, and Beck 1980). It is argued, in this perspective, that income returns are higher in primary-sector firms (variously defined) than in secondary ones. The proposed explanation is a structural one that emphasizes the linkage of jobs into hierarchical ladders in internal labor markets and the concomitant opportunity for occupational advancement and salary growth, which is influenced by educational attainment. Andrisani (1973) reported results consistent with this thesis, though his analysis has been faulted on methodological grounds by Cain (1976). For more recent support of 
the segmented labor market thesis, see Osberg, Apostle, and Clairmont (1987).

\section{EDUCATION AND PROMOTION}

An essential motivation for investigating promotion processes is the intimate linkage that this topic bears to the study of occupational achievement. Promotion is a principal means of growth in occupational status; as a consequence, investigations into the determinants of promotion (e.g., Wise 1975b; Medoff and Abraham 1980, 1981; Grandjean 1981; Rosenbaum 1979; Bielby and Baron 1983) have contributed to our comprehension of the dynamics of status attainment over the life course.

Promotion refers to change of rank within an organization. Rank, or grade level, differentiates among workers with respect to status, power, and salary; hence, any change in the determinants of promotion, as one moves up the organizational ladder, would reveal how an individual's ultimate occupational achievement is patterned by particular background variables. For example, while race and gender may have little impact on advancement prospects in low salary grades, it has been suggested (e.g., Kanter 1977, pp. 66-67; Auster 1988, p. 138) that these personal attributes are significant factors in promotion decisions at higher levels.

Few studies have examined how the determinants of promotion vary with organizational rank. Employees from different salary grades commonly are grouped together in an analysis (e.g., Wise $1975 b$; Bielby and Baron 1983; Medoff and Abraham 1980); in doing so it is implicitly assumed that the factors which influence advancement at one organizational level play a corresponding role at a different rank. Some exceptions are Rosenbaum (1979) and DiPrete and Soule (1988). The former documented diverse age $\times$ education effects on the promotion rate for three occupational groups; the latter, in an analysis of gender and advancement, reported quite different results by salary grade level.

In this article we examine the particular role of educational attainment in the promotion process. As we have intimated there are reasons for believing that the payoff to education is complex and is allocated among the different dimensions of educational achievement-years of schooling, credentials, school quality, and the like. ${ }^{2}$ There also are reasons for con-

${ }^{2}$ In an examination of the determinants of salary increases among school teachers, Spilerman (1986) reported that some school systems reward number of course credits beyond the baccalaureate, other systems reward advanced degrees but not course credits, and still others reward mixtures of the two education measures, in various combinations. 
sidering whether the impact of education (more precisely, its several components) differs by rank in an organization.

There is a basis for suggesting that the returns to education will vary with level in a firm. We expect, for example, graduate school training to be pertinent to job performance (and advancement, as a reward for superior work) in middle and senior grades, the organizational ranks in which relevant job skills are likely to have been imparted by specialized academic study. Similarly, we expect prestige of the undergraduate institution - an indicator of class and fraternal loyalties - to be salient to advancement in high salary grades because of the singular importance, at this level, of sponsorship and patronage for career success (Kanter 1977, pp. 61, 181-84).

The analysis in this paper is organized around a consideration of four facets of educational achievement: years of schooling, earned degrees, quality of the undergraduate school, and college major. Each facet has received some prior consideration with respect to occupational attainment, though not necessarily in a framework that explores its salience in a context of organizational rank. Some reasons for examining these educational features were noted in the introduction; to futher motivate the investigation we propose several hypotheses, which either represent inferences from the status attainment literature or, where that literature is lacking, summarize what appears to be common wisdom on the subject.

\section{Years of Schooling}

This variable measures general education, in contrast with firm-specific or job-specific training (Mincer 1974). General education enhances analytic and communicative skills and increases intellectual flexibility (Kohn 1969, pp. 183-88) and, presumably, adaptability in new job assignments-except where specific technical knowledge is required. Because jobs differ by salary grade in required level of education, as an entry prerequisite, matching models (e.g., Mobley 1982; Sørensen 1977, 1982) predict a corresponding variation between organizational rank and years of schooling.

A more refined formulation would note that the impact of an added year of study depends on current educational attainment, as well as on salary grade. In low organizational ranks an additional year after high school could contribute more to superior job performance (and advancement prospects) than an equivalent period of study after the bachelor's degree. This is because language and computation skills, which are crucial to success in clerical and secretarial positions, are mastered in secondary school or in the initial years of college. In high organizational ranks, in comparison, college and postgraduate study would be the critical levels 
of education that enhance job performance. This formulation suggests that, in each grade, the returns to schooling are nonlinear, with the inflection point-the educational level at which additional study has its greatest impact-increasing over the salary grades. ${ }^{3}$

\section{Credentials}

The empirical evidence concerning the importance of earned degrees, above years of schooling, is inconclusive. Faia (1981), analyzing data from the 1977 NORC General Social Survey (GSS), found a substantial impact of academic degrees on occupational prestige, but a weaker effect on earnings. Taubman and Wales (1973) also reached a favorable assessment about the contribution of earned degrees. Layard and Psacharopoulos (1974), in contrast, found little supporting evidence for credentials and concluded that, while "screening is a part of the explanation [of earnings differentials], . . . evidence suggest[s] that [it] is not a major part" (p. 995).

We examine two issues which bear on the role of credentials. First, extending the argument in the preceding section, we suggest that, if credentials matter, it is the academic degree most relevant to job performance in a particular grade that will have the greatest impact on advancement prospects from that rank. Thus, for example, business/secretarial certification and junior college completion should influence the promotion rate in low salary grades, while college and advanced degrees should play the same role in higher organizational ranks.

The second issue concerns the different meanings of credential effects, their formulation and measurement. In the framework of the human capital model, earned degrees, like years of schooling, are viewed as investments that increase cognitive skills, thereby enhancing productivity (Arrow 1973, Gintis 1971). In this formulation, a credential certifies completion of a program of study with a certain level of attainment. A variant of this thesis would have at least some of a credential's association with productivity arising from the sorting of individuals in school on the basis of ability (Taubman and Wales 1975, pp. 96, 110; Arrow 1973); in short, credentials would be seen as tapping heterogeneity among workers rather than differences in learned skills.

In either formulation it is presumed that an employer does not reward credentials, per se, but productivity. Both explanations are versions of the omitted variable problem: in a promotion regression a significant

\footnotetext{
${ }^{3}$ To be precise, we assume that the first derivative is positive and increasing with years of schooling for values below the inflection point, and positive and decreasing for values above the inflection point.
} 
credential term arises from the correlation of the credential with an unmeasured variable-learned cognitive skills in the first instance, innate ability in the second. It is the unmeasured variable, however, that is the true determinant of productivity (and promotion). It is not possible with our data to distinguish between these two formulations, as we lack measures of ability and cognitive skills. Both explanations predict significant additive effects of earned degrees, net of years of schooling.

By "credentialism" something different is intended. This concept refers to a tendency by employers to reward earned degrees, apart from any contribution they make to productivity (Faia 1981; Jencks et al. 1979, pp. 70-83; Harrison 1972, pp. 30-37). Such seemingly irrational behavior is explained in terms of the social value of credentials: a preference by firms for workers who have acquired conventional standards of sociability, who are culturally compatible, who are presumed capable of internalizing organizational goals, and who are therefore deemed "promotable" (Collins 1979, pp. 19-48; Meyer 1977). The empirical evidence in regard to this thesis is, however, contradictory (Blaug 1976, pp. 845-50).

A particular formulation of credentialism relates to optimization strategies available to a firm in a context of uncertainty about worker performance. With respect to promotion and salary decisions concerning new hires, Spence (1973) and Arrow (1973) observe that an employer might utilize credentials (or other attributes) as "signals" about expected productivity. With the passage of time the importance of a credential would decline, as performance records become available and supplant the need for a signal. Both Spence and Arrow note that if an employer correctly weighs the credential (signal), based on prior experience with its relation to performance, the credential term would provide an unbiased estimate of productivity differences between the groups; its effect (in a regression with productivity unmeasured) would not change as an employer shifts from reliance on the signal to an evaluation of a worker's performance record.

There is a basis, however, for suggesting that employers overweigh the signals. The credentialism literature speaks of rewards for earned degrees, even when they are only marginally associated with productivity. Such behavior is difficult to understand when a performance record is available for a worker, but in the absence of productivity information a manager may have good reason to be conservative. Hiring and advancement decisions involve training costs, and the dismissal of an unsatisfactory employee can be difficult and expensive. A cautious manager might choose to protect himself, in this circumstance, by advancing workers for whom credentials are available, so that he would be able to justify his decision in the case of a poor selection (Merton 1957, pp. 149-87; 
Thurow 1975, pp. 170-77). ${ }^{4}$ Under this thesis, credentials, initially, would be overrewarded, but the effect would decline with tenure, as performance data became available and replaced earned degrees as a basis for personnel decisions.

This latter formulation of credentialism - a variant of the "signal thesis" - can be distinguished from the skill-acquisition (or abilitysorting) explanation of credential effects in the following manner: under credentialism, net of years of study, we should find a positive effect for an earned degree and a negative effect for the interaction of the degree with seniority, indicating atrophy of the credential with time. Under the skill-acquisition explanation we should find an earned degree effect, but no significant interaction with seniority.

\section{College Quality}

Weisbrod and Karpoff (1968) and Wales (1973) reported a positive association between college quality and earnings; Wise $(1973 a ; 1973 b)$ found that college quality (measured by selectivity) is a strong predictor of both salary increase and promotion. In none of these studies was the effect examined by organizational rank. In line with our comments regarding years of schooling, we expect institutional quality to have its greatest impact in the salary grades in which college study contributes to job performance-presumably, the middle and senior ranks.

College quality has been interpreted as an indicator of the richness of the educational experience- "persons from better schools learn more than those in poorer schools, so their accrued academic knowledge is greater" (Wise $1973 a$, p. 363). On the other hand, quality schools probably attract more-able pupils (Addison and Siebert 1979, p. 135). In the absence of ability measures either contention-additional learning or heterogeneity-would produce a positive effect of college quality on promotion, an effect that would not erode with seniority.

College quality, however, could also be used by an employer, along with credentials, to screen new hires in a situation where few measures of productivity are available. If college quality were utilized in this way, as a "signal," then, following the formulation in the preceding section, a positive effect should be noted for new hires, but one that atrophies with seniority as direct measures of performance become available (i.e., negative interaction between school quality and seniority).

\footnotetext{
${ }^{4}$ Lester Thurow suggests that even if employers correctly assess the productivity differential associated with a signal, because of the zero-one nature of hiring and promotion decisions the preferred group will be overselected (1975, pp. 172-75). See Bielby and Baron (1986, p. 792) regarding other reasons for employers' misperception and misevaluation of workers' ability.
} 


\section{College Major}

In an analysis of the determinants of salary growth in "a large manufacturing corporation," Wise (1973a) reported information for three categories of college major. Controlling for other features of an individual's education record, he found a substantial positive impact for a science/ engineering major, a smaller effect for a liberal arts major, and the lowest efficacy for a business major.

Certainly the industrial specialty of a company is one determinant of the relevance of different college majors for advancement. However, we expect, in addition, a more or less universal association, across firms, between grade level and the returns to college major. In particular, in the middle ranks of a corporate bureaucracy, where the details of company policy are elaborated and their consequences extrapolated, employees who have concentrated in analytic fields-mathematics and the sciences-should be superior workers. In the highest corporate ranks the dominant activities are policy formulation, negotiation with external actors, and alliance building. A background in humanities or the social sciences would appear beneficial for these tasks. ${ }^{5}$

College major may also predict promotion because it is correlated with ability, broadly conceived, and we lack a measure of this construct. Thus, national Scholastic Aptitude Test (SAT) scores are highest for science and math majors, lower for social science majors, and still lower for students in education and business (College Board 1988, p. 8). However, if college major merely serves as a proxy for unmeasured ability, the major effects should not vary over the salary grades, as general ability-distinguished from specialized skills - should be universally valued. Finally, if college major is used by the firm to screen for prospective performance, then, following the signal argument outlined earlier, we should observe a decline with seniority in the effects of the major terms (i.e., negative interactions with seniority).

\section{DATA AND METHODS}

The data for this study were taken from the personnel records of a large insurance company with headquarters in the northeast. During the 1970s the company employed approximately 16,000 individuals at any given time. The information made available to us covers job histories within the company of all workers who either were employed as of year-end 1970 or entered employment between 1971 and 1978.

${ }^{5}$ Collins (1979, p. 32) makes a similar observation: "Specialized or technical skills are considered to be of minor importance, at least above the level of lower supervisory jobs." 
The company is hierarchically organized into salary grade levels (SGLs), from grade 1 (lowest) to grade 20 (highest). Above grade 20 are the vice presidential ranks, which are not part of the study (though promotion from grade 20 is included). The hierarchy is explicit in written documents, is clearly perceived by the employees, and provides the basis for the firm's definition of promotion-a grade increase. Aside from a small number of maintenance and craft workers (not included), the employees are white collar and are not unionized.

We analyze the rate of promotion for each of six groupings of salary grade levels (SGLs 1-3, 4-5, 6-7, 8-10, 11-14, 15-20). The clustering of multiple grades in the two highest categories results from the small number of employees in those ranks, given the pyramidal shape of the company. The regressions discussed below are based on a $30 \%$ random sample of workers in the two lowest SGL categories; on 50\% and $70 \%$ samples, respectively, in the next two categories, and on all employees in the two highest grade level groupings.

Promotions are investigated by means of a continuous-time transition rate model (Tuma and Hannan 1984). In particular, let the rate of advancement from grade $i$, after duration $t$ in the grade, be

$$
h_{i, i+1}(t \mid \mathbf{z})=\lim _{\Delta t \downarrow 0} P_{i}[t \leq T<t+\Delta t \mid T \geq t ; \mathbf{z}] / \Delta t,
$$

where $T$ is a random variable denoting months in grade $i, \mathbf{z}$ is a vector of covariates, and $P[\cdot]$ denotes a probability. Departures from the organization, demotions, and incomplete intervals were treated as censored observations.

Regarding the shape of the hazard (1), a Gompertz specification was used, ${ }^{6}$

$$
h_{i, i+1}(t \mid \mathbf{z}, \mathbf{x})=\exp \left(a t+\mathbf{b}^{\prime} \mathbf{z}+\mathbf{c}^{\prime} \mathbf{x}\right) \text {, }
$$

in which $\mathbf{z}$ is a vector of control variables, and $\mathbf{x}$ is a vector of covariates of interest-the education measures. The vector of controls contained the following terms: race (a set of four dummies), sex, age, seniority, and one or more grade-level dummies to correct for additive differences (in the exponent) in the effects of individual grades within an SGL category. To conserve space, only the coefficients of interest, for the education variables, are reported in the tables of regression equations.

The employee data base contains the following education information: (a) a set of 10 categorical variables that convey level of academic attain-

\footnotetext{
${ }^{6}$ As a test of the sensitivity to this assumption, several regressions were also run with a $\log$ logistic specification; they show little difference in covariate effects from the values reported in the tables.
} 
ment, ${ }^{7}(b)$ the name of the school from which the bachelor's degree was earned, and $(c)$ the college major. Several measures were constructed from these data.

\section{Years of Schooling}

In a few analyses, dummy variables, constructed from the categorical terms, were introduced directly into a regression; more often, a continuous formulation of years of schooling (EDUC) was used, which was created from the categorical terms. The assignment followed in defining EDUC is a fairly standard one: "high school graduate" was given the value " 12 ," "junior college degree" was coded " 14 ," "bachelor's degree" was assigned "16," and so on. In a few cases somewhat arbitrary assumptions were made: for example, "less than four years of high school" was assigned the value "10," "college courses, but less than 60 credits" was assigned "13."

\section{Credentials}

The 10 categorical variables are explicit with respect to highest earned degree and were the source of three credential dummies: business/secretarial graduate $(\mathrm{B} / \mathrm{S})$, junior college graduate $(\mathrm{JC})$, and master's degree (MA). In the analysis of credential effects our strategy was to introduce the three dummies together with variables for years of schooling (EDUC) and the square of this term. The dummies, then, convey the impact of credentials, net of the effect of length of study.

There is no dummy for bachelor's degree. Since the source of both the credential terms and EDUC are the 10 categorical variables, each credential is necessarily associated with a particular length of schooling. The consequence of including a credential dummy in the preceding formulation is to remove its years-of-schooling value from the estimation of the EDUC and (EDUC) ${ }^{2}$ coefficients. This is not a difficulty as long as a substantial number of observations remain, especially at the extremes of EDUC, to accurately estimate the two slopes. In the present study the many instances of "high school graduate" serve to anchor the low end of EDUC, in the context of dummies for B/S and JC. At the upper end, however, the inclusion of dummies for both bachelor's and master's degrees would have presented a problem.

\footnotetext{
${ }^{7}$ The categorical variables are: $E 0=$ less than four years of high school; $E 1=$ high school graduate; $E 2=$ high school plus secretarial/business school; $E 3=$ less than 60 college credits; $E 4=$ more than 60 college credits; $E 5=$ junior college degree; $E 6=\mathrm{BA}$ degree; $E 7=$ some graduate study; $E 8=$ master's degree; $E 9=$ doctorate.
} 


\section{Institutional Quality}

Selectivity was coded from Barron's (1980) Profile of American Colleges. In this volume, undergraduate-degree-granting schools are assigned to one of six categories on the basis of the difficulty of securing admission. A single variable was constructed from these ordered categories, with values ranging from one ("non-competitive") to six ("most competitive"). The few schools not listed in Barron's were assigned the value zero on the grounds that they are too minor to be included in the volume, even in the noncompetitive category.

Employees were assigned the selectivity score appropriate to their institution; workers who did not attend college were assigned the value zero. The selectivity measure was entered in a regression model together with a second variable, a dummy term (NO COLLEGE), coded " 0 " if the employee went to college and " 1 " otherwise. The resulting expression in the exponent of equation (2),

$$
b_{1}(\text { NO COLLEGE })+b_{2}(\text { SELECTIVITY }) \text {, }
$$

produces the following effect coding: $b_{2}$ (SELECTIVITY) if the employee attended college and $b_{1}$ otherwise.

\section{College Major}

Four dummy variables were created to summarize a variety of fields of study: social science/humanities, business/insurance, math/science/engineering, and a residual category, NO COLLEGE. The last term also includes a very few employees who attended college but for whom a major was not reported.

Means for the controls and the education variables are reported in table 1 . There are few surprises in this material, and we note only the principal patterns. Turning to the controls, duration in a grade rises with rank, but the differences are not large. With respect to race, the representation of blacks and Hispanics declines sharply over the grades; their percentages in the highest SGL category are less than one-tenth their rates in the lowest grades. The gender effect is similar: percentage female declines from $91 \%$ in the lowest SGL category to $8.5 \%$ in the highest corporate ranks.

The education variables also reveal expected patterns. Years of schooling (EDUC) increases over the grades, as does the proportion of employees holding a master's degree. In contrast, there is a decline in the proportions with $\mathrm{B} / \mathrm{S}$ and $\mathrm{JC}$ as their highest credential. The college selectivity variable reported in the table is adjusted to reflect only employees who attended college. This measure fails to reveal any trend over the grades 


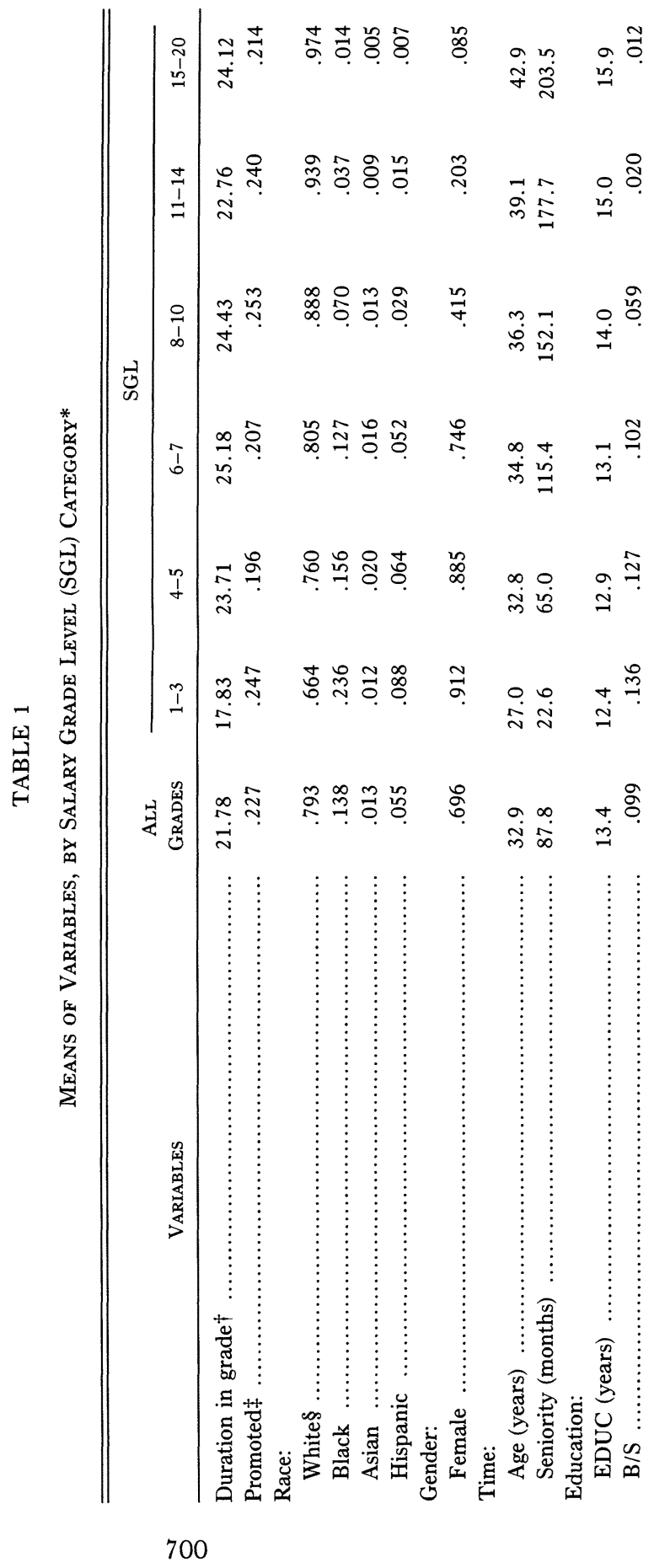




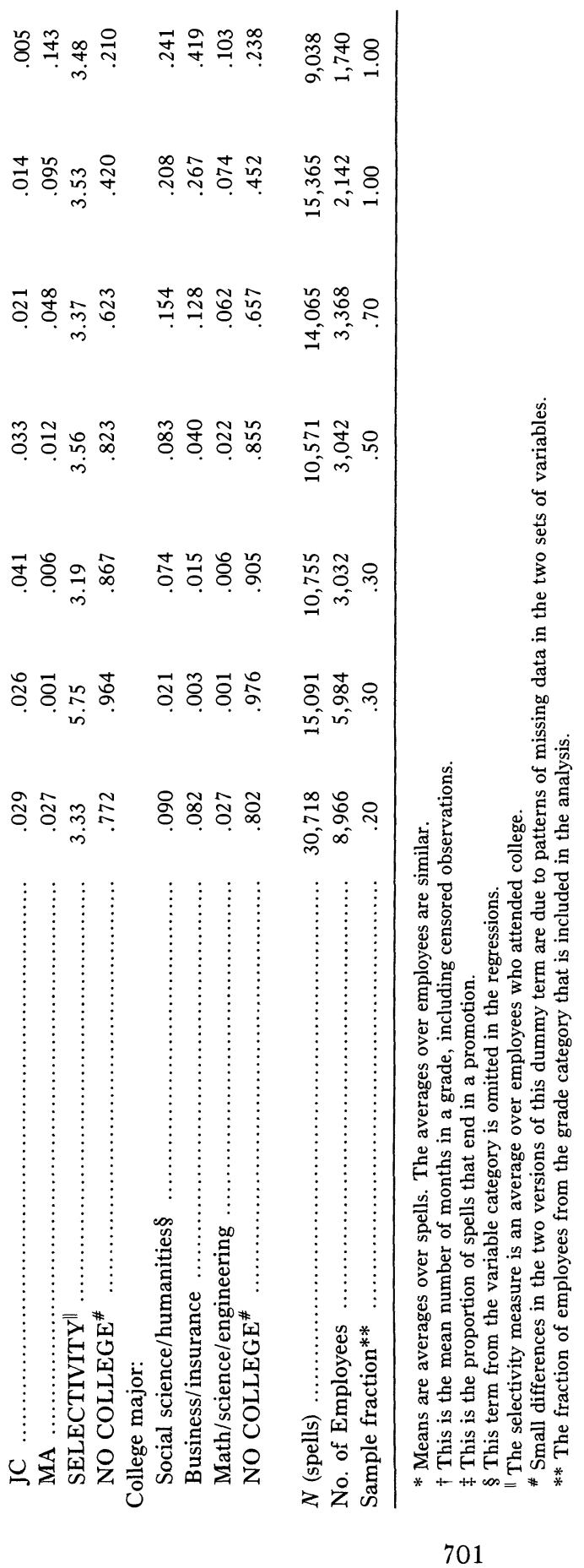


in college quality; the one anomaly, the high score in the lowest SGL category, should be discounted as it is based on a small number of cases. The distribution of college majors, by salary grade, is more interesting and shows an increase in business/insurance and math/science/engineering specialties, relative to social science/humanities, as one moves up the corporate ranks.

\section{FULL SAMPLE RESULTS}

In table 2 we report findings from the analysis of a representative $20 \%$ sample of employees from all grade levels. The education terms in each column were estimated via a model of the form (2), in which controls were present for gender, race, age, seniority, and SGL level.

What we observe in table 2 are the following: $(a)$ a strong tendency for promotion to be associated with years of schooling (col. 1), the effect being linear in the exponent (note the insignificance of $\mathrm{EDUC}^{2}$ in col. 2); (b) a credential effect, but only for business/secretarial graduate, with a negative influence on promotion (cols. 3,4$)$; and (c) rather clear evidence of promotion being associated with college selectivity and with a math/ science/engineering major (cols. 5, 6). The final three columns fail to reveal any significant interactions with seniority.

The returns to years of schooling, college selectivity, and math/science/ engineering major are consistent with results reported by others (e.g., Wales 1973; Wise 1975b; Pfeffer 1981, pp. 347-52). The credential effects are more surprising, in regard to both the negative sign of the significant $\mathrm{B} / \mathrm{S}$ dummy and the failure to find a contribution from an advanced degree. Also noteworthy is the lack of evidence for a "signal" thesis, at least in its present formulation.

Before commenting on the credential effects it should be noted that they are not a result of constraining the years-of-schooling variable to be linear. Equations (3) and (4) reveal virtually identical results, whether the credential coefficients are measured as deviations from a linear or a quadratic function of EDUC. Nor is the negative $\mathrm{B} / \mathrm{S}$ finding a consequence of an incorrect assignment of years-of-schooling to this degree. Equation (3) was reestimated, with the business/secretarial degree varied between 12 and 13 years, without the negative effect being altered appreciably.

This negative credential is consistent with two explanations: (1) selfselection by high school graduates with limited ability or modest ambition into a secretarial/business training program, in which case, in the absence of ability or ambition measures, the $\mathrm{B} / \mathrm{S}$ term would serve as a proxy for these variables; or (2) a learning process, in which the credential measures skill acquisition associated with completion of the training program. 


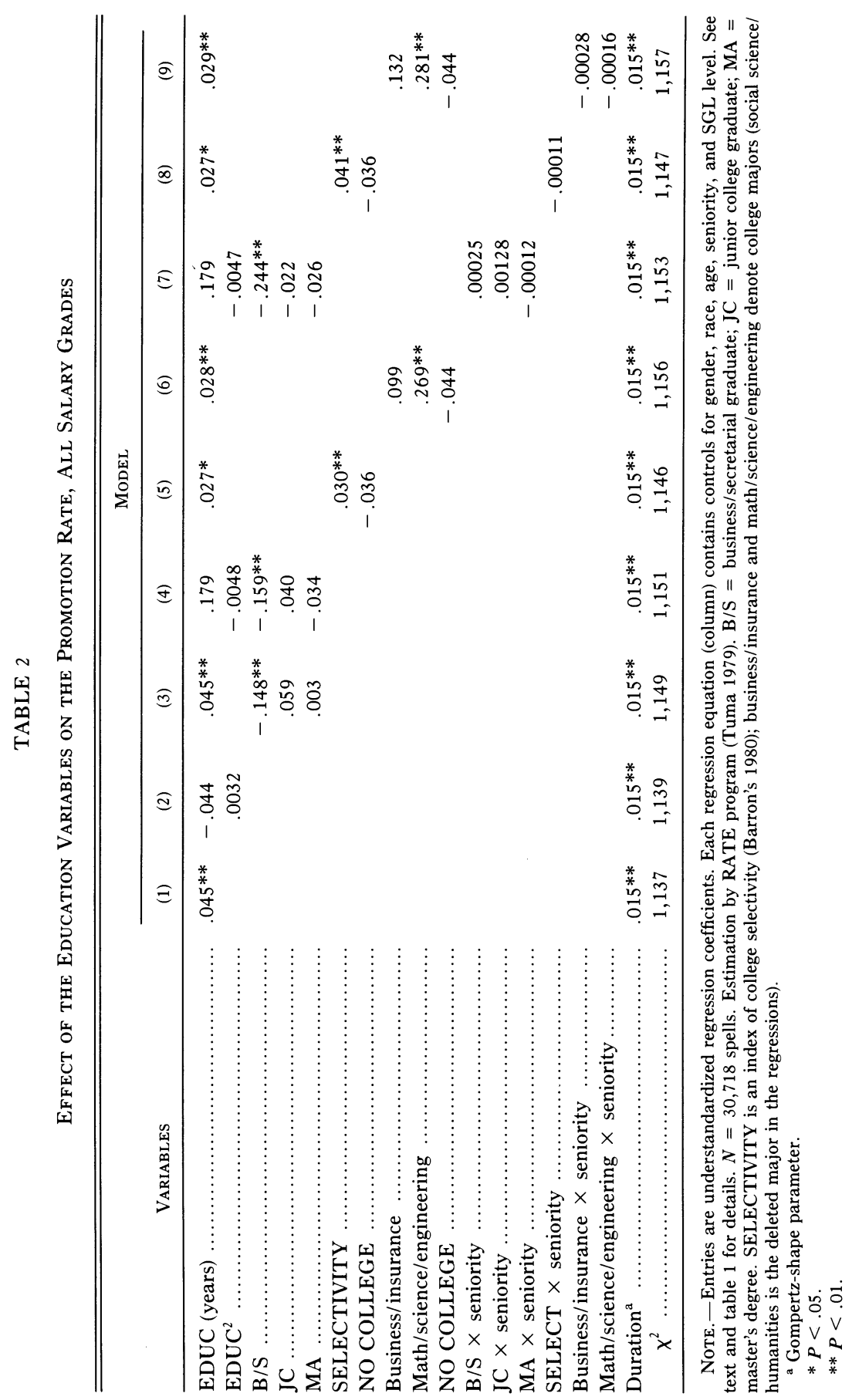


Normally, with our data, we cannot distinguish between the two explanations. In the present case, however, we discount the learning thesis because it is difficult to associate a negative effect with "learning" and because, as noted, the coefficient remains negative even when the $\mathrm{B} / \mathrm{S}$ credential is equated (in years of study) with the high school graduate level; that is, no credit given for time spent in post-high school training.

The preceding discussion was intended to provide summary information about the impact of the different educational features on occupational advancement, as well as to assess whether our results replicate the reports of researchers who have investigated other firms. Our findings appear to be typical of large corporate bureaucracies, enhancing our confidence in the generalizability of the results. We now turn to an analysis of the variation in educational effects over the salary grades.

\section{RETURNS TO EDUCATIONAL ATTAINMENT, BY ORGANIZATIONAL RANK}

\section{Years of Schooling}

What is the impact of length of study on advancement prospects? In part A of table 3 we report, by SGL category, regressions of the promotion hazard on EDUC; each model is of the form (2) and contains controls for gender, race, age, seniority, and detailed SGL. Here EDUC appears as a linear variable in the exponent of these equations. Quadratic functions of EDUC were also estimated; however, in no case was the quadratic term significant.

The returns to years of schooling, viewed across the SGL categories, describe a unimodal curve (top row). The returns are small in the lowest and highest grades, and peak in the middle ranks. One explanation for this curvilinear pattern was provided by personnel managers in the insurance company: in the lowest grades, they contend, promotions are largely scheduled and require little more than acceptable attendance and the meeting of minimum performance standards. Thus, differences in schooling among employees do not get expressed in the promotion rate. In the highest ranks, in comparison, it is leadership style, personality, and political alliances - rather than educational attainment - that determine advancement. ${ }^{8}$ Only in the middle ranks, where bureaucratic competence

\footnotetext{
${ }^{8}$ In some instances loyalty is rewarded directly by appreciative superiors. More commonly, social linkages and appropriate personal characteristics facilitate job performance. (As a result, a manager could make promotion decisions on the basis of universalistic criteria-i.e., productivity-even though particularistic considerations underlie the performance differences.) In either case, the impact of schooling is lessened.
} 


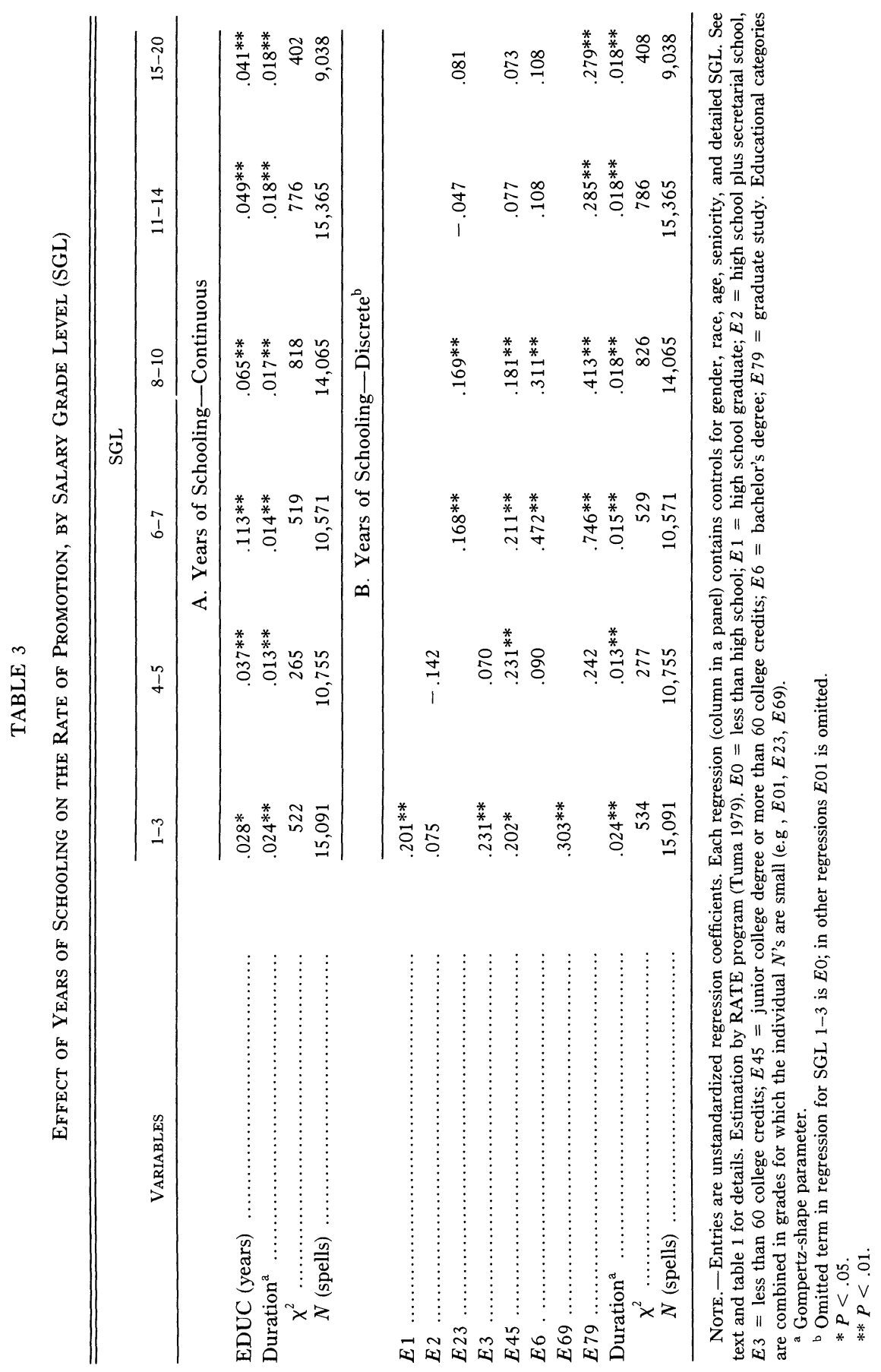


and analytic skills are critical for carrying out the more or less routine supervisory and technical tasks, does length of study have a substantial impact on promotion. It is in these grades that employees are sorted, with respect to future advancement, on the basis of human capital measures.

The preceding account represents management's view of the reward structure. A somewhat different insight is obtained from an examination of part B, in which educational attainment is represented by a series of dummy terms. Ignoring, for the moment, the depressed value of $E 2$ in SGLs $1-3$ and $4-5,{ }^{9}$ in four of the six SGL categories the shape of the promotion response to years of schooling is consistent with a step-function formulation. Further, the inflection point - the locus of maximum gain from additional schooling-increases over the ranks: in the lowest SGL category the distinction of importance is the shift from "less than high school" $(E 0)$ to "high school graduate" $(E 1)$; in the next grade category it is the shift from "some college" $(E 3)$ to "junior college/more than 60 credits" $(E 45)$ that is rewarded, ${ }^{10}$ and in the two highest SGL categories only graduate training $(E 79)$ contributes to the promotion rate.

These results provide support for the contention that, at each organizational level, certain educational skills are critical to job performance, and it is principally the acquisition of these skills that is rewarded. Additional schooling that does not bring one up to the critical level for a grade does not appear to be translated into a corresponding increase in the promotion rate-the results for SGLs 11-14 and 15-20 are informative on this point. Correspondingly, additional study above the level at which the skills crucial for task performance are imparted also receives little recognition in the promotion rate-see SGLs 1-3 and 4-5.

The results for the middle SGL categories (6-7 and 8-10) reveal a different pattern. In the former the education effects are linear; in the latter the results are ambiguous. These promotion responses may reflect a situation in which years of schooling enhances job performance over the full range of the education variable. Alternatively, the observed results could derive from the fact that the occupational tasks are very heterogeneous; these grades contain the highest rungs of the clerical job ladders as well as the entry steps of the professional/administrative lines. As a consequence, the response patterns may represent mixtures of more basic step-functions for the component jobs. ${ }^{11}$

\footnotetext{
${ }^{9}$ The term $E 2$ denotes "high school graduate plus secretarial/business school." In the next section we argue that this kind of postsecondary training is associated with a negative credential effect, one that is superimposed on the returns to years of schooling. This result is also apparent from models (3) and (4) of table 2.

${ }^{10}$ We attribute the fluctuations in the terms following $E 45$, in SGL $4-5$, to the relatively small numbers of college graduates and postgraduates in low salary grades.

${ }^{11}$ Some evidence for a mixture interpretation was obtained by allocating employees
} 
In regard to promotion, then, the evidence is fairly clear that the returns to schooling vary with organizational rank. Use of a single linear variable suggests that the impact of an additional year is greatest in the middle salary grades. However, when schooling is represented by a series of dummy terms, a more refined explanation is suggested, one in which a particular length of study is seen as critical to job performance (and advancement) in each salary grade. Thus, in low ranks, where clerical and secretarial tasks predominate, the crucial skills involve a facility with basic arithmetic and acquaintance with English language rules-for which high school completion and, perhaps, some college would suffice. In the highest grades of the company, in comparison, the critical skills involve mastery of subjects such as marketing, investment, and actuarial science, and it is therefore advanced academic training that is rewarded.

\section{Credential Effects}

Six credentials are recorded in the employee data base: high school graduate, business/secretarial school graduate, junior college degree, bachelor's degree, master's degree, and doctorate. The effect of a doctoral degree was not investigated, as the number of employees with this degree is very small. Also, for reasons noted earlier, dummy terms were not defined for high school graduates or recipients of the bachelor's degree. This analysis, therefore, is restricted to the contributions of three levels of certification: business/secretarial graduate, junior college degree, and master's degree.

By "credential effects" we refer to the impact of earned degrees on the promotion rate, net of the returns to years of schooling. In part A of table 4 we report, for each of the six SGL groupings, the results from a hazard formulation (eq. 2), with variables present for EDUC, (EDUC) ${ }^{2}$, the credential terms, and the aforenoted controls. Even though (EDUC) ${ }^{2}$ is highly correlated with EDUC, the quadratic term is introduced so that the credential dummies are measured as deviations from a years-ofschooling function which is not constrained to be linear (in the exponent). ${ }^{12}$

in the middle SGL categories between clerical and administrative lines of work. In SGL $6-7$, for example, the clerical lines have the dummy effects $.053, .124, .402 *$, $.540 *$ for $E 23-E 79$, respectively $(* P<.01)$; in short, there is little impact of education before level $E 6$.

${ }^{12}$ Without $\left(\right.$ EDUC) ${ }^{2}$ present, the variable EDUC is significant and has values that approximate those given in pt. A of table 3. The credential terms from a linear formulation of EDUC show effects that are similar to, but somewhat stronger than, the ones reported in table 4 . The quadratic expression in the text is the more conservative formulation for estimating the magnitude of the credential terms. 


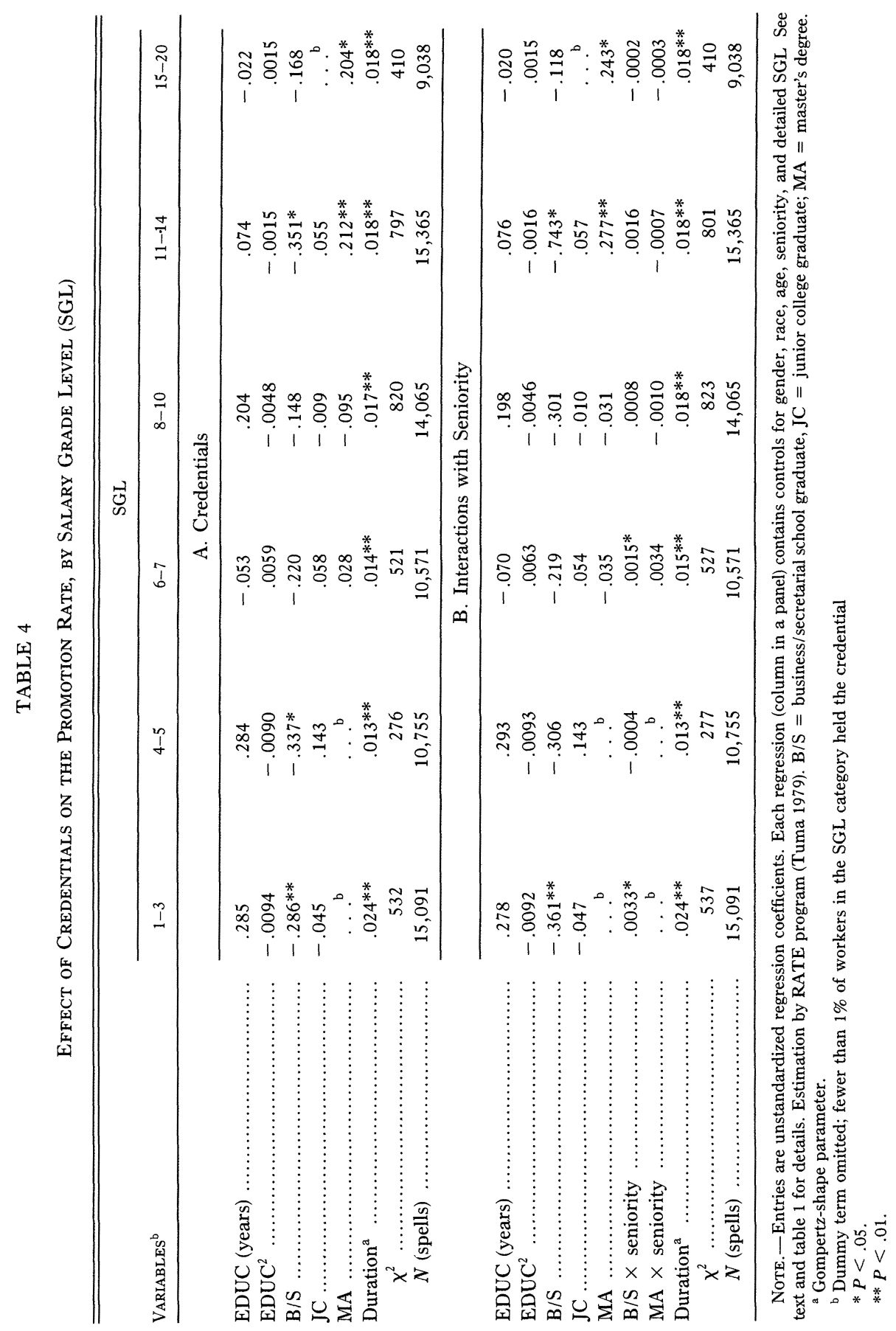


We observe, in table 4, part $\mathrm{A}$, consistent negative returns across the salary grades to business/secretarial study; the effects are significant in the two lowest grade categories and in SGL 11-14. Completion of a master's degree is rare in the lowest salary grades (less than $1 \%$ of observations); a dummy term for this credential was therefore omitted. In the middle SGL categories the returns to master's degree are small and insignificant; in the two highest salary grade categories, however, the coefficient for a master's is positive and significant. The junior college term is fairly small in magnitude and insignificant in all grades.

With one exception the business/secretarial term is significant only in the lowest SGL categories, and the MA term only in the highest salary grades. One is tempted to interpret these results as supporting a thesis of reward allocation by firms for the academic degree most relevant to job performance in the particular rank; in short, a formulation that parallels the conclusions reached with the years-of-schooling dummies. Yet the results for the two credentials are really quite different. The MA effects support this contention-the dummy variables are small except in the grades in which the skills associated with advanced academic training would be useful. The B/S term, however, is negative and substantial in all salary grades; its insignificance in the higher SGLs is probably due to the rarity of this credential in senior ranks rather than to a lessening of effect on the promotion rate.

Now, there is no reason to expect the different credentials we investigate to all have the same consequence for advancement, and there is no necessity, therefore, for performing a universal test of a "credential effect." An employer might use some degrees as "signals," while discounting others; some credentials may provide skills specific to task performance in certain jobs and in the associated grades, while others are diffuse in their impact (Spence 1973, p. 359). In line with this reasoning, in the analysis of interaction effects (table 4, pt. B), our strategy is to examine separately the pattern for each degree. ${ }^{13}$

With respect to a master's degree, the interaction with seniority is never significant. This suggests that its impact on the promotion rate does not atrophy with length of service; there is no evidence for "credentialism," in the sense of a signal invested with elevated significance in the absence of performance measures. Rather, a master's degree increases one's promotion prospects independent of employment duration. The further result (from pt. A) that the MA effect operates only in the highest

${ }^{13}$ The junior college effects were small in all our test runs and the interactions with seniority were never significant. As a result, the interaction terms were omitted in the final regressions. 
salary grades reinforces our earlier assessment, from table 3 , that it is academic training relevant to job performance which is being rewarded.

In comparison, the interactions of the $\mathrm{B} / \mathrm{S}$ terms with seniority are contradictory. In SGLs 1-3 and 6-7 the positive interactions support a "credentialism" interpretation: In the absence of performance measures, employers act as if it is individuals with modest ability, or low career aspirations, who undertake this training; in short, the credential is disvalued. With the passage of time, the impact of the credential is mitigated (positive interaction with seniority) as performance data become available. In other SGLs, however, the interaction term is insignificant, suggesting that while this degree may be correlated with (omitted) determinants of performance, the degree itself is not treated by employers as a signal.

Rather than propose different explanations by salary grade level, we restrict our assessment concerning the $\mathrm{B} / \mathrm{S}$ degree to the consistent results with the additive terms (table 4, pt. A). From this material, it is evident that a $\mathrm{B} / \mathrm{S}$ credential has a negative effect, one that is universal across salary grades. Whether the depressed promotion rate is a result of selfselection into secretarial training by workers of modest ability (no interaction) or whether employers initially stigmatize workers having this educational background (positive interaction) remains unclear.

To summarize, academic degrees do have an effect, net of years of schooling, but the evidence for "credentialism"-as the thesis is formulated in this paper-is modest. Rather, we find that a master's degree increases the rate of promotion in the higher salary grades, where the skills associated with this degree can enhance work performance. A business/secretarial certificate influences the advancement rate for a different reason; either in fact or in the stereotypical views of employers, it is associated with weak job performance or low career aspirations. ${ }^{14}$

\section{College Quality}

Wise $(1975 b)$ reported a positive effect of college selectivity on the promotion rate. Our results, using the full sample (col. 5 of table 2), corroborate

\footnotetext{
${ }^{14}$ To be certain that our results are not an artifact of the coding scheme, we performed the following sensitivity analyses: We varied the EDUC value for B/S from 12 to 13 years, which corresponds to an average length of secretarial study of zero to one year. We also varied the length of study assigned to the master's degree from one to two years. The results from these assignments differed only modestly from the values presented in the text and did not alter the thrust of our assessment.
} 
his findings. We also noted the absence of an interaction with seniority (col. 8), which suggests that college quality is not used by employers as a "signal" regarding expected productivity.

The motivation for examining the impact of college quality by organizational rank derives from the conclusions to the preceding sections. In particular, we have observed that both years of schooling (EDUC) and a master's degree have effects that vary by salary grade, and that the pattern of these effects conforms to a formulation in which employers reward educational attainment that is consistent with work requirements in a particular rank. Now, college quality does not tap level of academic attainment. Nonetheless, it seems reasonable to postulate that in the jobs (and grades) in which college training contributes valued skills, graduation from an institution of superior standing would signify an enriched education. For this reason, we expect college selectivity-our indicator of quality-to predict promotion, especially in the middle and senior organizational ranks.

In table 5 we report hazard regressions, with the variables of interest coded in accordance with the formulation of equation (3). The results in part A provide only modest support for our contention. Selectivity, indeed, is positive and significant in grades 8-10 and 11-14. However, the magnitude of the selectivity coefficient is equally large in lower SGLs, raising the possibility of insignificance in those ranks only because of the paucity of employees with college training. Further, there is no evidence of a selectivity effect in the highest SGL category.

Part $\mathrm{B}$ is revealing about this ambiguity. Here the selectivity effects are significant and substantial in grades 6-7 through 11-14. Further, the interactions with seniority are also significant-and negative-in the three SGL categories. These findings suggest that college selectivity is used as a "quality signal" by employers in regard to the expected performance of recent hires (Pfeffer 1981, p. 352), much as has been argued with respect to earned credentials. The quality signal is utilized in initial promotion decisions, in the middle organizational ranks, where college training would provide relevant job skills. The interaction effect in the highest SGLs, though not significant, is consistent with this argument; the insignificance probably reflects the small number of individuals hired directly into the senior ranks.

In summary, in regard to college quality, we find considerable evidence in support of a "signal" thesis, with a further indication that the signal is activated, principally, in the middle grades. The absence of a significant interaction in the representative sample of company employees (col. 8 of table 2) is misleading with respect to the true role of college quality in promotion decisions and can be attributed to the large proportion of the 


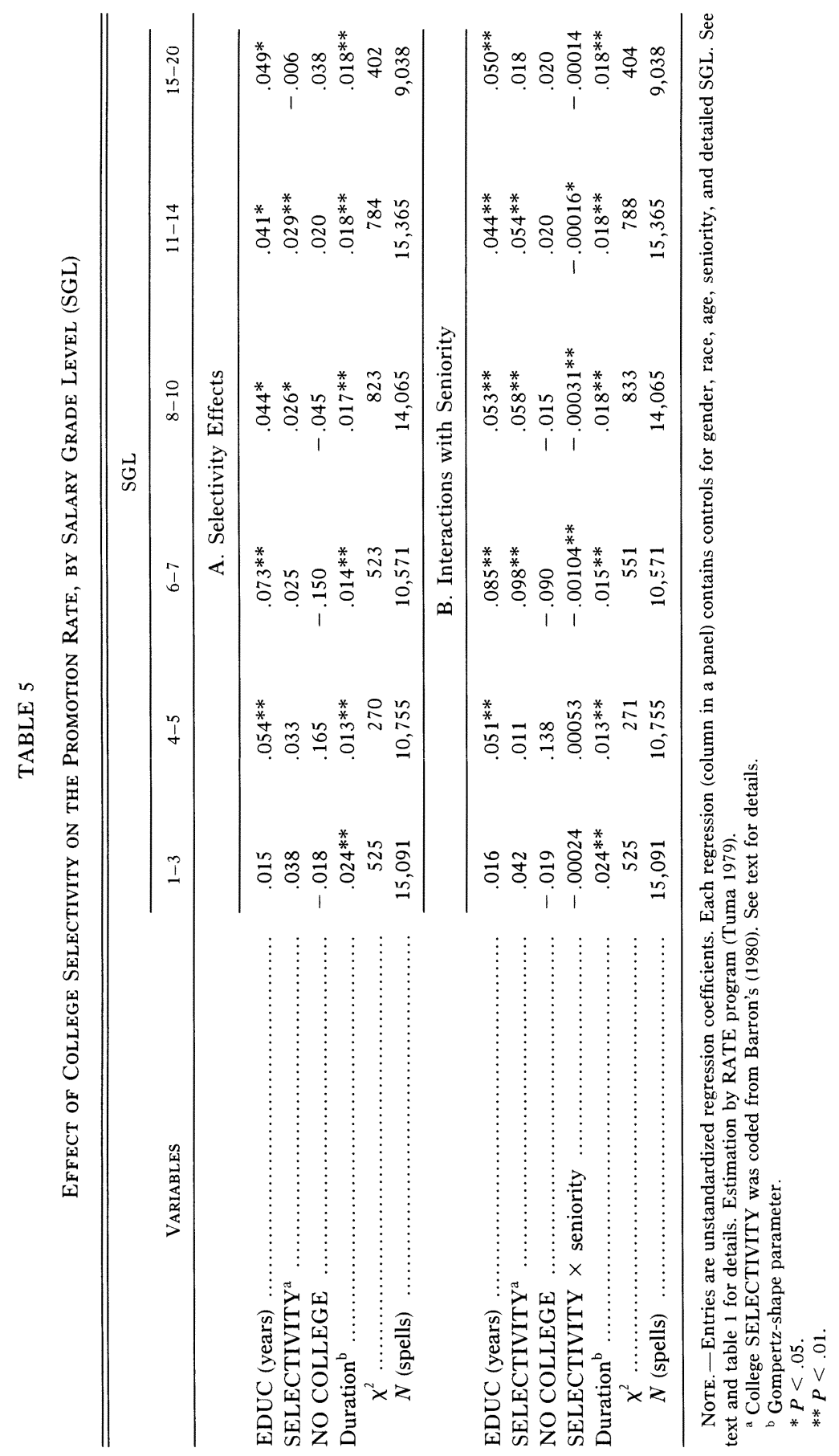


work force engaged in low salary grades, where advanced study has little impact on job performance.

\section{College Major}

Wise $(1975 b)$ reported a significant effect of a math/engineering major on the probability of promotion; our results with the representative sample of employees confirm his findings (col. 6 of table 2). Also, since the interactions with seniority (col. 9) are insignificant, a thesis to the effect that college major is used by employers as a "productivity signal" fails to find support, at least in its current formulation.

At the outset of the paper we suggested that college major might serve as a proxy for ability (unmeasured in our data base). This possibility is credible because a math/science concentration is, indeed, associated with high SAT scores (College Board 1988, p. 8). If this omitted variable thesis is correct, then a math/science major should have a positive effect on the rate of promotion in all $S G L s$, since general ability, presumably, would enhance work performance in every rank. An alternate possibility is that the math/science/engineering major contributes to productivity only in jobs that require advanced analytic skills-presumably positions in the middle organizational ranks (Pfeffer 1981, pp. 346-50). A third thesis is that some majors are used by an employer as "signals," relied upon as peformance indicators for newly hired workers. Akin to the credentialism formulation, a significant interaction with seniority would constitute support for this contention.

The impact of field of study on the rate of promotion is addressed in table 6 , in which survival regressions are reported. The reference category for the college major effects is social science/humanities; relative to this specialty there is a clear indication that a math/science/engineering concentration is advantageous, with respect to the promotion rate, in all salary grades except SGL 11-14 (pt. A). ${ }^{15}$ The reason for the lack of effect in the latter grade category could not be ascertained.

The introduction of interaction terms between college major and seniority does not alter the findings with respect to a math/science/engineering concentration: in no case is the interaction term significant (table 6, pt. B). However, a significant interaction (negative) between business major and seniority does appear in the middle grades-SGLs 6-7 and 8-10. In conjunction with the positive main effects, this result suggests

${ }^{15}$ The effect of the NO COLLEGE term (positive and significant in SGL 15-20) has no evident substantive interpretation. The EDUC variable in these regressions controls for years of schooling; the dummy for no college is included to obtain a proper specification of the college major terms. 


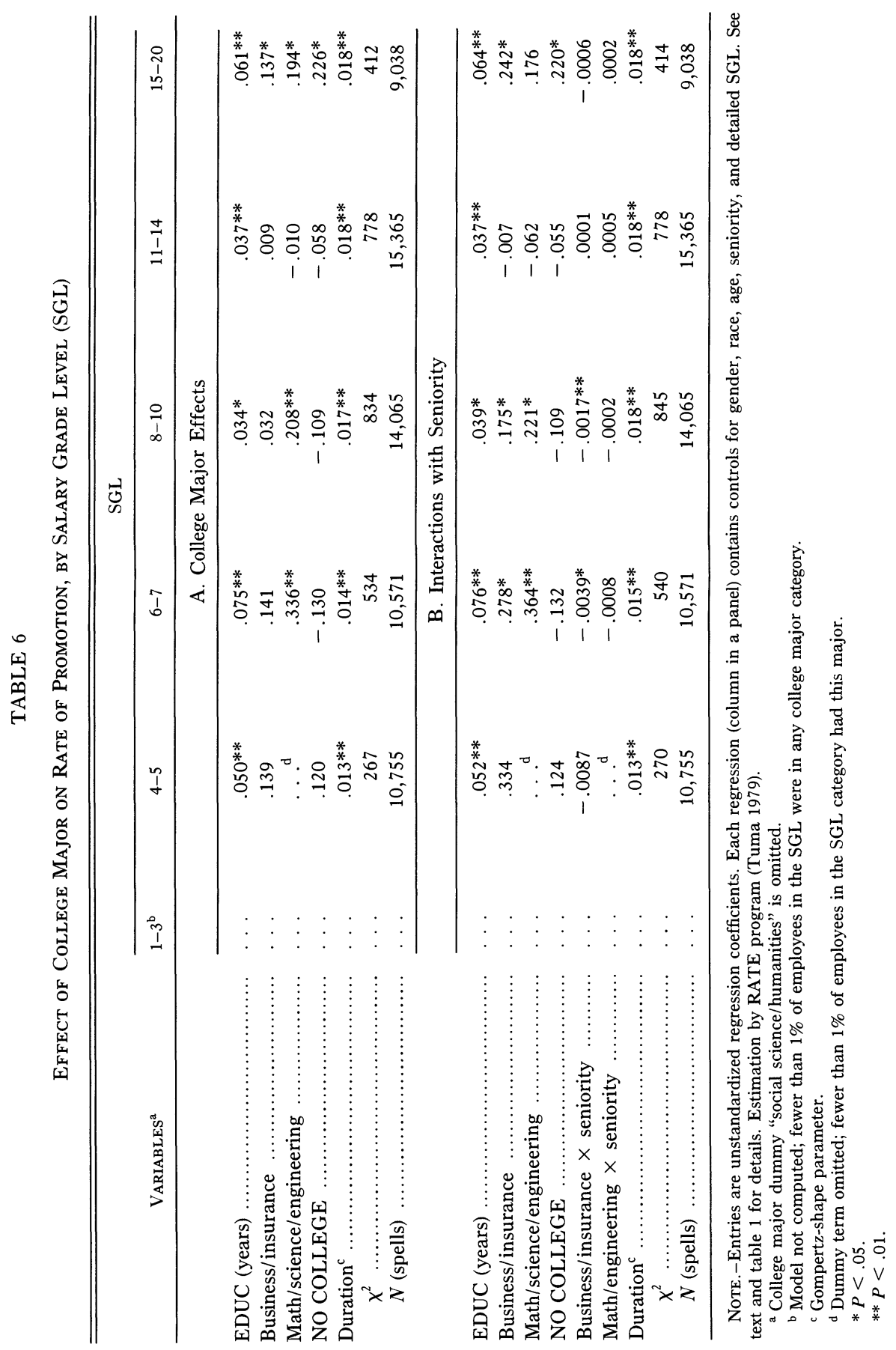


that the business major is invested with special significance by employers, relied upon as a "signal" of competence or commitment, in the absence of performance information.

With respect to college major we conclude that a math/science/engineering concentration does increase the rate of promotion, either because more-able students self-select into this specialty or because the associated skills are useful in insurance company jobs. Because a match/science/ engineering major is rare in the two lowest grade categories, it is not possible to choose definitively between these explanations, such as by examining whether this specialty enhances the promotion rate in low ranks, where advanced mathematics would have little relevance for job performance. (Nonetheless, the broad range of grades in which a math/ science/engineering concentration is significant speaks for ability sorting as the more likely explanation.) There is no indication that this major is accorded particular significance by employers (no interaction effect); a contrary conclusion, however, should be drawn with respect to a college major in business studies.

\section{CONCLUSIONS AND IMPLICATIONS FOR THEORY ABOUT ATTAINMENT PROCESSES}

The objective of this paper was to investigate the promotion returns to different educational features, giving special consideration to how the returns vary with position in an organization. With respect to an individual's educational biography, it is evident that each of the factors-years of schooling, earned degrees, college quality, and college major-bears some influence on advancement prospects.

The way in which these educational components contribute to the promotion rate is clarified once considerations of organizational rank are introduced. Indeed, the principal finding from this analysis is that employers reward schooling to the extent it is relevant to job performance; as a result, the particular educational features that predict to advancement vary with salary grade and, presumably, with other job characteristics as well.

Whether one views employers as rewarding educational attainment directly, or indirectly via its effect on job performance, it is not the case that scholastic attainment is compensated indiscriminately; with respect to promotion prospects, "more is not necessarily better." Rather, the greatest impact of education occurs at the point at which supplementary schooling is likely to convey job relevant skills. Additional study that is below the threshold for effectiveness in a work setting produces little impact on the promotion rate; schooling in excess of the educational requirements for a job appears to be treated by employers as superfluous. 
Support for this assertion is evident with respect to years of study (pt. B of table 3), though much the same conclusion can be drawn from an evaluation of the master's credential and college quality.

\section{The Matching of Workers and Jobs}

It would seem that these findings are at variance with the job matching literature. In that literature a dynamic formulation of career evolution is proposed in which the rate of job changing corresponds to the discrepancy between an individual's resources and a job's requirements-the rate is highest when the fit is poor and it slows down with age (or seniority), as experience with prior job tasks permits workers and employers to arrive at a suitable "match" (Jovanovic 1979; Mobley 1982, pp. 96-118; Sørensen 1977 , 1982). ${ }^{16}$ What we find, instead, is that the rate of promotion (job changing) is maximum when the fit between education and job requirements is best and lower when educational attainment is insufficient for effective task performance.

This apparent contradiction between the matching literature and our findings is resolved once we consider which actor-worker or employer-controls the job-change decision. Termination of employment, especially from large companies, is primarily at the initiative of the worker, ${ }^{17}$ though firms are not without strategies for encouraging the departure of unwanted employees. In general, if a worker is displeased with the match, if he feels that his resources make him worthy of a better job, he will look elsewhere. With the passage of time the worker, presumably, succeeds in arriving at a suitable match-either because a more satisfying position has been found or because his appraisal of his own resources has been lowered-and the rate of job changing declines.

Promotion, however, represents a different kind of job change. This decision is made by the employer, not by a worker. It is based on a worker's productivity record; as such it is a reward for superior performance. What we find is that the rate of promotion peaks when there is a good match between a worker's educational background and the requirements of his current job, and it is lower when the match is poor. Sørensen (1977, p. 972) and Jovanovic (1979, p. 976), incidentally, make clear that their job matching formulations refer to the calculations of workers; from the perspective of an employer the intent is to motivate

\footnotetext{
${ }^{16}$ Sørensen (1977, p. 972) uses a slightly different formulation of career evolution; he bases the rate of mobility on the discrepancy between an individual's current attainment and potential attainment, given his or her resources.

${ }^{17}$ Aside from cyclical layoffs, dismissals are not common because of contractual and legally mandated due process procedures. At the insurance company, for example, $14 \%$ of terminations during 1971-78 were classified as "involuntary."
} 
and reward productivity, which is heightened, presumably, when the correspondence is optimal.

With regard to career dynamics, our results suggest the following strategic considerations for a worker: It is important to enter an organization at a rank in which one's educational attainment is not much above the norm for the grade, because superior education provides little return in promotion prospects. With advancement, at the point where one's educational qualifications fit the prerequisites for the job, one is advantaged with respect to less educated workers but not handicapped in reference to better-trained employees. With further promotion the worker begins to find himself at a disadvantage with respect to better-schooled employees, as the scope of job requirements is extended.

These results are reminiscent of the "Peter Principle"- the cliché which predicts that individuals will rise to the level of their incompetence. Stated more formally, we would say that individuals rise to the level at which their resources match a job's qualifications; after this point the rate of advancement begins to decline. Yet, this appraisal should be qualified for employees who have reached the highest salary grades of a company. From our results, and from reports of others (e.g., Kanter 1977, pp. 181-86; Pfeffer 1981, pp. 251-54), it appears that educational attainment has little impact on advancement within senior management ranks; considerations of sponsorship, networks, and alliances are more relevant factors.

\section{Specific Educational Features}

Aside from these remarks about the dynamics of the advancement process, there are findings specific to particular educational components. Ignoring minor inconsistencies we would say that a secretarial credential and a math/science/engineering major have effects that are invariant of rank, while a master's degree influences the promotion rate only in grade levels in which advanced academic skills are likely to contribute to productivity.

This assessment is based on the additive effects of the different educational terms. Formally, in this instance, with our data, we cannot differentiate between an explanation that stresses ability sorting and one that emphasizes learning. In actuality, the secretarial effect is likely to arise from a selection process. Evidence for this assertion resides in the negative character of the credential (difficult to attribute to learning) and in the universality of its effect over the salary grades. We suspect that the math/science/engineering term also reflects an ability-sorting processbecause of the lack of grade-level specificity-but the evidence here is far from conclusive. In comparison, the MA effect, which is specific to 
the higher ranks, probably represents a learning process-the acquisition of skills necessary for productivity in these grades.

A final theme concerns the evidence for "credentialism"; more generally, for a "signal" hypothesis in which the signal is some educational feature that an employer chooses to invest with elevated significance. We find evidence that college quality and a business major function in this capacity. Moreover, each variable is credible as a signal in a context of uncertainty. College quality (or its correlate, prestige) has been cited as a factor upon which employers rely even when an association with productivity is not evident (Pfeffer 1981, p. 352). Similarly, a business major indicates commitment to the corporate world; one can imagine a preference for such workers when training investments have to be made and performance information is lacking.

Nonetheless, we hesitate to make much of the evidence for a signal thesis. First, the variables traditionally associated with credentialismearned degrees - fail to exhibit the pattern associated with this mechanism. Second, we lack a theory that would suggest which educational features are likely to be accorded significance or how the salience of the different features might vary by firm or industry. In this circumstance, our results - that some educational features exhibit "signal" effects while others do not-remain little more than interesting empirical regularities. We are in a somewhat different situation with respect to the additive effects of math/science/engineering major, school quality, and business/ secretarial study. The first two corroborate the reports of Wise (1975b) and Wales (1973); at least we are on surer empirical footing. The negative secretarial terms are credible because they are strong, consistent over the salary grades, and not counterintuitive.

\section{REFERENCES}

Addison, John T., and W. Stanley Siebert. 1979. The Marketfor Labor: An Analytical Treatment. Santa Monica, Calif.: Goodyear.

Andrisani, Paul J. 1973. "An Empirical Analysis of the Dual Labor Market Theory." Ph.D. dissertation. Ohio State University, Department of Economics.

Arrow, Kenneth J. 1973. "Higher Education as a Filter." Journal of Public Economics 2 (July): 193-216.

Auster, Ellen R. 1988. "Behind Closed Doors: Sex Bias at Professional and Mangerial Levels." Employee Responsibilities and Rights Journal 1(2):129-44.

Barron's. 1980. Profile of American Colleges. New York: Barron's Educational Series.

Bielby, William T., and James N. Baron. 1983. "Organizations, Technology, and Worker Attachment to the Firm." Pp. 77-113 in Research in Social Stratification and Mobility, ed. Don Treiman and R. Robinson. Greenwich, Conn.: JAI.

1986. "Men and Women at Work: Sex Segregation and Statistical Discrimina-

tion." American Journal of Sociology 91, no. 4 (January): 759-99. 
Blau, Peter, and O. D. Duncan. 1967. The American Occupational Structure. New York: Wiley.

Blaug, Mark. 1976. "The Empirical Status of Human Capital Theory: A Slightly Jaundiced Survey." Journal of Economic Literature 14:827-55.

Cain, Glen G. 1976. "The Challenge of Segmented Labor Market Theories to Orthodox Theory: A Survey." Journal of Economic Literature (December): 1215-57.

College Board. 1988. 1988 Profile of SAT and Achievement Test Takers. New York: College Entrance Examination Board.

Collins, Randall. 1979. The Credential Society. New York: Academic Press.

DiPrete, Thomas A., and Whitman T. Soule. 1988. "Gender and Promotion in Segmented Job Ladder Systems." American Sociological Review 53 (February): 26-40.

Faia, Michael A. 1981. "Selection by Certification: A Neglected Variable in Stratification Research." American Journal of Sociology 85, no. 5 (March): 1093-1111.

Gintis, Herbert. 1971. "Education, Technology, and the Characteristics of Worker Productivity." American Economic Review 62 (May): 266-79.

Grandjean, Burke D. 1981. "History and Career in a Bureaucratic Labor Market." American Journal of Sociology 86 (March): 1057-92.

Harrison, Bennett. 1972. Education, Training, and the Urban Ghetto. Baltimore: Johns Hopkins University Press.

Jencks, Christopher M., M. Smith, H. Acland, M. J. Bane, D. Cohen, H. Gintis, B. Heyns, and S. Michaelson. 1972. Inequality. New York: Basic.

Jencks, Christopher M., S. Bartlett, M. Corcoran, J. Crouse, D. Eaglesfield, G. Jackson, K. McClelland, P. Mueser, M. Olneck, J. Schwartz, S. Ward, and J. Williams. 1979. Who Gets Ahead? New York: Basic.

Jovanovic, Boyan. 1979. "Job Matching and the Theory of Turnover." Journal of Political Economy 87 (October): 972-90.

Kanter, Rosabeth M. 1977. Men and Women of the Corporation. New York: Basic.

Kohn, Melvin L. 1969. Class and Conformity: A Study in Values. Homewood, Ill.: Dorsey.

Layard, Richard, and George Psacharopoulos. 1974. "The Screening Hypothesis and the Returns to Education." Journal of Political Economy 82:985-98.

Medoff, James L., and Katherine G. Abraham. 1980. "Experience, Performance, and Earnings." Quarterly Journal of Economics 95 (December): 703-36.

- 1981. "Are Those Paid More Really More Productive? The Case of Experience." Journal of Human Resources 14(2): 186-216.

Merton, Robert K. 1957. Social Theory and Social Structure. Glencoe, Ill.: Free Press.

Meyer, John W. 1977. "The Effects of Education as an Institution." American Journal of Sociology 83, no. 1 (July): 55-77.

Mincer, Jacob. 1974. Schooling, Experience, and Earnings. New York: National Bureau of Economic Research.

Mobley, William H. 1982. Employee Turnover: Causes, Consequences, and Control. Reading, Mass.: Addison-Wesley.

Osberg, Lars, Richard Apostle, and Don Clairmont. 1987. "Segmented Labor Markets and the Estimation of Wage Functions." Applied Economics 19:1603-24.

Osterman, Paul. 1975. "An Empirical Study of Labor Market Segmentation." Industrial and Labor Relations Review 28:508-23.

Pfeffer, Jeffrey. 1981. Power in Organizations. Marshfield: Pitman.

Reynolds, Lloyd G. 1978. Labor Economics and Labor Relations. Englewood Cliffs, N.J.: Prentice-Hall.

Rosenbaum, James A. 1979. "Organizational Career Mobility: Promotion Chances in a Corporation during Periods of Growth and Contraction." American Journal of Sociology 85:21-48. 


\section{American Journal of Sociology}

Sicherman, Nachum. 1991. "Over-education in the Labor Market." Journal of Labor Economics (in press).

Spence, Michael. 1973. "Job Market Signalling." Quarterly Journal of Economics 87 (August): $355-74$.

Sørensen, Aage B. 1977. "The Structure of Inequality and the Process of Attainment." American Sociological Review 42 (December): 965-78. . 1982. "Processes of Allocation to Open and Closed Positions in Social Structure." Harvard University, September. Typescript.

Spilerman, Seymour. 1986. "Organizational Rules and the Features of Work Careers." Pp. 41-102 in Research in Social Stratification and Mobility, ed. Don Treiman and R. Robinson. Greenwich, Conn.: JAI.

Taubman, Paul J., and Terrence J. Wales. 1973. "Higher Education, Mental Ability, and Screening." Journal of Political Economy 81 (January/February): 28-55.

. 1975. "Education as an Investment and a Screening Device." Pp. 95-122 in

Education, Income, and Human Behavior, ed. F. Thomas Juster. New York: National Bureau of Economic Research.

Thurow, Lester C. 1975. Generating Inequality. New York: Basic.

Tolbert, Charles M., Patrick M. Horan, and E. M. Beck. 1980. "The Structure of Economic Segmentation: A Dual Economy Approach." American Journal of Sociology 85:1095-1116.

Tuma, Nancy B. 1979. Invoking RATE, 2d ed. Menlo Park, Calif.: SRI International.

Tuma, Nancy B., and Michael T. Hannan. 1984. Social Dynamics. New York: Academic Press.

Wachter, Michael L. 1974. "Primary and Secondary Labor Markets: A Critique of the Dual Approach." Brookings Papers on Economic Activity, no. 3, pp. 637-80.

Wales, Terrence J. 1973. "The Effect of College Quality on Earnings: Results from the NBER-Thorndike Data." Journal of Human Resources 8:306-15.

Weisbrod, B., and P. Karpoff. 1968. "Monetary Returns to College Education, Student Ability and College Quality." Review of Economics and Statistics 50 (November): 491-97.

Welch, Finis. 1973. "Black-White Differences in Returns to Schooling." AmeriEconomic Review 63 (December): 893-907.

Wise, David A. 1975a. "Academic Achievement and Job Performance." American Economic Review 65:350-66.

1975b. "Personal Attributes, Job Performance and Probability of Promotion." Econometrica 43:913-31. 